rare with B. para. A. They were not agglutinated by paratyphoid or Gaertner sera, and showed a moderate degree of pathogenicity to guinea-pigs. The other strain, XXXIX. 2, was peculiar in not fermenting dulcite at the first testing, but in having all the reactions of B. para. $B$ or B. Gaertner at the second testing, five months later. In our examinations of Dardanelles troops at the M.E. laboratory under Captain Archibald, R.A.M.C. $\left(1916^{8}\right)$, one of our greatest difficulties was the distinction between true paratyphoid bacilli and harmless "paratyphoid-like" bacilli. Fifteen such inagglutinable strains were obtained by blood culture from cases of undoubted paratyphoid fever. In infants such organisms are in like manner a source of difficulty, but in the present series of cases appeared to be unconnected with the diarrhoea.

Other non-lactose-fermenting bacilli of Groups $\mathrm{H}$ and $\mathrm{J}$ (Lewis) were obtained from normal cases, while a bacillus of Group I. was obtained from a diarrhoea case.

Observations of a ward epidenic of diarrhoea.-The mode of incidence of the following six cases is of interest.

Case XLI. was admitted to a ward in the beginning of November, 1912. From a specimen examined on Nov. 3rd bacilli resembling Morgan's No. 1, save that they liquefied gelatin, were isolated.

Case XLIII. had been admitted to this ward in September suffering from empyema (XXXI.). She was then free from diarrhoea, and a "paratyphoid-like" bacillus was isolated from the stool. On Nov. 16th she developed acute diarrhoea with blood and mucus. From a specimen Morgan's No. 1 bacillus was isolated. A highly agglutinating serum was prepared from strain XLIII. 6.

Case XLII. was admitted to the ward on Nov. 5th suffering from lobar pneumonia. On Nov. 18th she developed acute diarrhoea with blood and mucus in the stools. On Nov. 19th Morgan's No. 1 bacillus was obtained from a specimen. The child died on Nov. 23rd. The Morgan's No. 1 bacillus from this case was not agglutinated by serum XLIII. 6, and therefore did not belong to the same subgroup of the Morgan's No. 1 group.

Case XIIV. was admitted to the ward on Nov. 13th. On Nov. 19th very severe diarrhoea with passage of blood and mucus started. On Nov. 24th an inagglutinable dysentery bacillus of Flexner-Y type was isolated. The child died on Nov. 25th.

It will be observed that in these four cases, all in the ward at the same time, and three of them starting acute diarrhoea within a period of three days, the non-lactose-fermenters isolated nere different in each case.

Another case (XXIX.) was admitted to the ward in October suffering from diarrhoea. On Oct. 15th Morgan's No. 1 bacillus was isolated from her fæces. On Oct. 30th she was convalescent, and a second examination at this date again produced Morgan's No. 1 bacillus, along with a "paratyphoidlike" bacillus (XXXIX.). In the latter part of November and in December she had another very severe bout of diarrhoea, but a specimen was not examined during this period. On Jan. 6th she had completely recovered and from her stool at this date (specimen XLV.) was isolated a dysentery bacillus, inagglutinable, with Flexner-Y reactions. This child was in the ward at the same time as Case XLIV., from whom a similar organism was isolated.

The last case of this series, XLVI., was admitted to the ward in December, suffering from chronic diarrhoea, along with an ischio-rectal abscess. Towards the end of December his diarrhoea became very acute and of dysenteric type. On Jan. 6th a dysentery bacillus, inagglutinable, with Flexner-Y reactions, was isolated from his stool. The child died on Jan. 9th.

It is reasonable to suppose that the cases from which specimens XLIV., XLV., and XLVI. were obtained were (1) infected one from the other, or (2) infected from a common source. When specimen XXXIX. was obtained from the second child her flora was still of the diarrhoea type and harboured Morgan's No. 1 bacillus, and was therefore probably less protected against the onslaught of a dysentery bacillus. That this child was still harbouring a dysentery bacillus after complete recovery from diarrhcea directs attention to the carrier problem in dysentery of infants as well as of adults.

The cases XLI. to XLIII. still remain a puzzle. They occurred in apparently epidemic form, and yet the nonlactose-fermenter isolated was different in each case. Is the explanation possibly that Cases XLI. to XLIII, were suffering from true dysenteric infection, but that the secondary overgrowth in the intestine of other non-lactose-fermenters had concealed the presence of the dysentery bacilli? Is it that there are several varieties of non-lactose-fermenters which are capable of producing a diarrhœea or even an inflammation or ulceration of the intestine? Or does a common cause produce conditions in the intestine permitting the overgrowth of non-lactose-fermenters as a result rather than a cause of the diarrhoa? It is impossible without further research to answer these questions.

I would again lay stress on the differences between the flora of breast-fed children and of children on artificial diet, and on the exaggeration of the same differences when one proceeds further to the flora of children suffering from a diarrhoea. In my first paper it was pointed out how completely the acid-tolerant group is able to outgrow the nonlactose-fermenting group in a medium containing lactose or glucose, the acid produced by the splitting of the sugar rapidly killing off the latter group of organisms. It is possible that the acid-tolerant group plays a beneficent part in restricting the growth of these organisms, and that any cause, chemical or otherwise, which inhibited the growth of the acid-tolerant group might set up a diarrhoea by thus permitting an overgrowth of members of the nonlactose-fermenting group. Further work on these lines is desirable, and the relative immunity to diarrhoea of breastfed children should be taken as a starting-point.

Summary.-Fourteen cases of diarrhcea were all on artificial diet at the time of onset. The flora of artificially fed infants differs from that of breast-fed infants chiefly in a decrease of the acid-tolerant group, an increase of the normal $B$. coli group, and in the appearance of members of the non-lactosefermenting group along with some increase of cocci. The flora of infants suffering from diarrhcea shows similar but more marked changes, and the more severe the diarrhœa the more marked the changes. It is probable that the acidtolerant group exerts a beneficent influence in restraining the growth in the intestine of the non-lactose-fermenting group.

Bacilli of the non-lactose-fermenting group were obtained from 6 out of 21 ( 28.5 per cent.) infants and young children who were free from diarrhœa. Bacilli of this group were isolated from 11 out of 14 cases of diarrhoea ( 78.5 per cent.). Bacilli of Morgan's No. 1 group were isolated from 9 per cent. of the normal children, and from 35 per cent. of the cases of diarrhoea.

True, though non-agglutinable, dysentery bacilli were isolated from none of the normal children, but were obtained from three cases of diarrhoea with blood and mucus (dysentery), or 21 per cent. of total diarrhœa cases. A certain number of cases of diarrhoa of infants are therefore true bacillary dysenteries, even in Scotland and in winter-time.

It is doubtful whether the overgrowth of non-lactosefermenting bacilli initiates the diarrhoea, or whether it is a secondary and aggravating factor.

Literature.-1. Logan : Journ. of Patk. and Bact., vol. xviii., p. 527 1914. 2. Flexner and co-workers: Studies from the Rockefeller Institute 1904, vol. ii. 3. Morgan : Brit. Med. Jour , 1906, vol. i., p p. 1911. 4 Morgan and Ledingham : Proc. Roy. Soc. Med., 1909, ii., 2, Epidemio logical Section. 5. Lewis : Annual Report of Medical Officer of Local Government Board for 1910-11, Appendix B, No. 2. 6. Lewis : Ibid. for 1911-12, Appendix B, No. 2. 7. Lewis : Ibid. for 1912-13, Appendix $\mathbf{B}$ No. 3. 8. Archibald, Hadfield, Logan, and Campbell : Jour. of R.A.M.C., June, 1916 .

\section{AN IMPROVED OPERATION FOR INTRINSIC MALIGNANT DISEASE OF THE LARYNX.}

BY H. LAMBERT LACK, M.D. LOND., F.R.C.S. ENG., SURGEON TO THE THROA'T DEPARTMENT OF THE LONDON HOSPITAL.

Is February last I demonstrated an improved operation for the removal of malignant growths of the vocal cords, and in April I described the method more fully in the Journal or Laryngology. The improvement consisted essentially in removing a portion of the laryngeal cartilages on the affected side. The steps of the operation are briefly as follows.

The larynx and the upper rings of the trachea are exposed through the usual vertical median incision and a tracheotomy tube is inserted. Then the soft tissues and perichondrium are turned off the thyroid cartilage on the affected side; the crico-thyroid membrane and the ring of the cricoid are laid bare. Next, if desired, thyrotomy is performed by splitting the thyroid cartilage in the median line in the usual way. By gentle traction on the margins of 
the opening thus made the interior of the larynx can be inspected and the nature and extent of the growth seen. With strong cutting forceps the growth, with a sufficient margin of healthy tissue, is now cut away, together with the overlying cartilage in one piece. The taking away of the cartilage together with the underlying soft parts ensures not only a more thorough removal of the growth, but gives a much better view of the parts which are being divided, and much freer access for the use of instruments in the interior of the larynx.

The thyrotomy is not always necessary. When it is known that the growth is malignant and that it is limited to one vocal cord there is no need to split the thyroid. With a small saw the thyroid cartilage is divided in the median line from its lower edge upwards nearly to the upper margin. A transverse incision is then carried backwards just below the upper edge of the thyroid, nearly to the posterior border, and then downwards just in front of the posterior border. The square piece of cartilage thus marked out is removed, and subsequently the larynx is opened by dividing the underlying soft parts.

The following advantages were claimed for the operation.

1. It ensures more thorough removal of the disease by giving a free view of the parts to be removed, as well as by taking away the overlying cartilage.

2. The operation is rapid and easy.

3. Bleeding is easily controlled and the great danger of the operation-blood entering the air-passages and causing difficulty with the anæsthetic and subsequently septic pneumonia-is avoided.

4. After the operation the patient is able to swallow without difficulty or pain, which is not always the case with thyrotomy when there has been much wrenching apart of the cartilages.

5. Healing is rapid, and there is no subsequent necrosis of a fragment of cartilage, such as occasionally follows an ordinary thyrotomy.

6. The after-results as regards the voice are excellent and there seems no danger of subsequent larnygeal stenosis.

The advantages of this method, and more especially that of being able to see plainly the parts which are being divided and thus of being able to arrest immediately every bleeding point, have led me to simplify the operation. As all hæmorrhage can be immediately arrested the preliminary tracheotomy is obviously a useless and unnecessary complication. Being able to dispense with tracheotomy the usual vertical incision down the front of the neck can be replaced by a curved transverse incision. The advantages of the transverse incision, both with regard to rapidity of healing and the subsequent cosmetic effect, need hardly be mentioned. The transverse incision gives a better view of the parts to be removed and heals with hardly any scarring or puckering. Also, it is more superficial and less extensive, and the deeper tissues in the lower part of the neck are not opened up. Thus there is less risk of sepsis, and healing is more rapid.

This operation I recently carried out in the case of a feeble man, aged 72, with epithelioma of the right vocal cord. The man was suffering from general atheroma and cardiac degeneration, as well as from chronic emphpsema and bronchitis. He was therefore a bad subject for a prolonged anæsthetic and especially for an operation upon the air-passages. It was essential that the operation should be performed quickly, that no blood or fluid should enter the windpipe during the operation, and that there should be no trouble in swallowing subsequently. Naturally also the smaller and the more superficial the wound and the quicker the healing, the more likely he was to survive. Under chloroform anæsthesia a curved horizontal incision was carried across the front of the larynx at the level of the crico-thyroid membrane. The tissues being divided down to the larynx the crico-thyroid membrane, the upper edge of the cricoid ring, and the right half of the thyroid cartilage were freely exposed. With a small saw the thyroid cartilage was divided in the median line from its lower edge nearly to the notch in its upper border. A cut almost at right angles to this was carried backwards just below the upper edge of the thyroid cartilage, and then another vertical incision was made near the posterior edge of the cartilage, so as to mark out a square of cartilage and leaving intact both the posterior and upper borders of the thyroid. The piece of cartilage thus marked out was detached from the soft parts underlying it with a blunt dissector and removed. All bleeding being arrested the interior of the larynx was cartully opened in the median line through the crico-thyroid membrane and upwards along the course of the first incision in the cartilage above described. Then an incision was carried backwards along the lower border of the crico-thyroid membrane as close to the cricoid ring as possible, and the edges of the triangular flap thus marked out being retracted the interior of the larynx and the growth could plainly be seen. The growth, with a sufficient margin of surrounding healthy tissue, was now detached on a third side by a horizontal incision carried well above it, and finally dissected posteriorly off the arytenoid cartilage. All this cutting was carried out piece by piece and every bleeding point being picked up at once, the growth was removed without a drop of blood entering the air-passages. The operation up to this point occupied barely 35 minutes. Some time was now spent in allowing the wound to become "glazed" by exposure to the air and letting the patient come almost out of the anæsthetic, so that no possible source of subsequent bleeding should be left. When the wound was quite dry the edges of the skin were brought together by two stitches, except for a small gap at its centre which was left open for drainage. A simple dressing was applied and the patient returned to bed. He made an uninterrupted recovery without any complications. He was in a very feeble condition, and I feel sure that he could not have stood a severe operation or even a prolonged anæsthetic.

'This operation is both safer and more thorough than the ordinary thyrotomy. It is safer because (1) it is simpler and therefore more rapidly performed; (2) it allows free access to the field of operation and therefore complete facility for dealing with hænorrhage; (3) the smaller and more superficial wound entails less danger of sepsis ; (4) the transverse incision heals more quickly; and (5) tracheotomy is quite unnecessary and is therefore omitted. It is more thorough because (1) it allows a good view of the parts to be removed and (2) the overlying cartilage is also removed. These advantages are obtained without any corresponding risks or disadvantages. I believe, therefore, that it will be the method of choice in the future, and that thyrotomy, except as a purely exploratory operation, will no longer be practised. Devonshire-place, $\mathrm{w}$.

\section{THE ORIGIN AND PREVENTION OF CEREBRO-SPINAL FEVER.}

By HALLIDAY SUTHERLAND, M.D. Bdin.,

TEMPORARY SURGEON. ROYAL NAVY: CONSULTING TIBERCULOSLS OFFICER FOR NORTH MARYLEBONE. LONDON; AND MEDICAL OFFICER TO THE ST. MARYLEBONE TUBERCULOSIS DISPENSARY.

IT may be that if the causes and prevention of cerebrospinal fever had been less simple they would have been more generally accepted by the profession to-day.

\section{The Speeifie Organism.}

The diplococcus intracellularis meningitidis of Weichselbaum conforms to Koch's law for pathogenic organisms. Constantly found in the tissues and body fluids of the victims of epidemic cerebro-spinal meningitis, the meningococcus may be isolated in pure culture, is able to reproduce the disease in monkeys, can be recovered from the lesions in these animals, and is therefore the causal organism of cerebro-spinal fever.

Apart from the monkey, man is the only animal in whose nervous system specific lesions are produced by this organism Starting, then, with the proved proposition that the meningococcus is the sole cause of cerebro-spinal fever. it is possible to show, with the exactness of a problem in Enclid. the means whereby man is infected, the conditions under which he develops the malady, and the method of preventing both infection and disease.

Conditions Determining the Spread of Infection.

At times when the disease is not prevalent meningococei have been found in the throats of 2 per cent of healthy soldiers. ${ }^{1}$ Among healthy naval ratings, not known to have 